\title{
Vax genes ventralize the embryonic eye
}

\author{
Stina H. Mui, ${ }^{1,2,4}$, Jin Woo Kim, ${ }^{1,4}$ Greg Lemke, ${ }^{1,5}$ and Stefano Bertuzzi ${ }^{3}$ \\ ${ }^{1}$ Molecular Neurobiology Laboratory, The Salk Institute La Jolla, California 92037, USA; ${ }^{2}$ Department of Neurosciences, \\ University of California, San Diego, La Jolla, California 92039, USA; ${ }^{3}$ Dulbecco Telethon Institute, National Research \\ Council-Institute of Biomedical Technologies, 20090 Segrate (Milan), Italy
}

\begin{abstract}
The vertebrate retina and optic nerve are strikingly different in terms of their size, organization, and cellular diversity, yet these two structures develop from the same embryonic neuroepithelium. Precursor cells in the most ventral domain of this epithelium give rise only to the astrocytes of the optic nerve, whereas immediately adjacent, more dorsal precursors give rise to the myriad cell types of the retina. We provide genetic evidence that two closely related, ventrally expressed homeodomain proteins-Vax1 and Vax2-control this neuroepithelial segregation. In the absence of both proteins, we find that the optic nerve is transformed in its entirety into fully differentiated retina. We demonstrate that this transformation results from the loss of ventralizing actvity in the developing eye field, and that ventralization is mediated, at least in part, via Vax repression of the Pax6 gene, a potent inducer of retinal development.
\end{abstract}

[Keywords: Retina; homeobox; Pax6; development; mouse]

Received October 27, 2004; revised version accepted April 6, 2005.

Developmental boundaries within the embryonic neuroepithelium frequently establish and constrain the differentiation potential of neural stem cells, and this is dramatically so for the developing eye. The evaginated neuroepithelium that gives rise to the eye-the optic vesicle-buds from the ventral diencephalon of the embryonic brain (Chow and Lang 2001). During this process, a sharp dorsoventral territorialization occurs, with the optic disk separating the ventral optic stalk from the more dorsally positioned presumptive retina. The optic stalk, which is apposed to the midline source of the ventralizing morphogen sonic hedgehog (Shh), develops into the optic nerve (Marti and Bovolenta 2002). The presumptive retina, which is further removed from, and receives a lower dose of this morphogen, develops into the neural retina (NR) proper (Chow and Lang 2001; Figs. $1 \mathrm{~A}, \mathrm{~B}, 2 \mathrm{~A}-\mathrm{C})$. These dramatic differences in tissue morphogenesis are mirrored in neuroepithelial cell differentiation; cells that are segregated into the ventral optic stalk undergo limited rounds of cell division and differentiate into only a single cell type-optic nerve astrocytes (Mi and Barres 1999). In marked contrast, adjacent cells that are segregated into the presumptive NR become retinal progenitor cells (RPCs), which undergo many more rounds of cell division and differentiate asynchronously into diverse cell types, including retinal ganglion cells (RGCs), photoreceptors, amacrine cells, bipolar cells, horizontal cells, and Müller glia (Livesey and Cepko 2001).

\footnotetext{
${ }^{4}$ These two authors contributed equally to this work.

${ }^{5}$ Corresponding author.

E-MAIL lemke@salk.edu; FAX (858) 455-6138.

Article and publication are at http://www.genesdev.org/cgi/doi/10.1101/ gad.1276605
}

Although dosage manipulations of Shh have demonstrated that the levels of this morphogen are critical to dorsal-ventral patterning of the optic vesicle (Macdonald et al. 1995; Chiang et al. 1996; Ohkubo et al. 2002), the intracellular effectors of Shh in the eye field have remained elusive. We have previously reported on two closely related transcription factors-encoded by the ventral anterior homeobox (Vax) genes 1 and 2-whose expression domains and loss-of-function phenotypes in the mouse are consistent with their functioning as such effectors (Bertuzzi et al. 1999; Mui et al. 2002). We now describe the remarkable phenotypes seen in the developing eye field of Vax1/Vax2 double-mutant embryos, in which the optic nerve is transformed into retina. We demonstrate that Vax1 and Vax2 normally act in concert to ventralize this field, and that they achieve this through repression of the Pax6 gene. The Vax proteins thereby drive the development of a ventral structure, the optic nerve, by inhibiting the development of its more dorsal neighbor.

\section{Results}

Genetic interaction between Vax1 and Vax2

From approximately embryonic day 13.5 (E13.5) onward, the mouse Vax1 and Vax2 genes exhibit nonoverlapping patterns of expression (Bertuzzi et al. 1999; Hallonet et al. 1999; Barbieri et al. 2002; Mui et al. 2002); Vax1 is expressed in the optic stalk (Fig. 1C), while Vax2 is expressed in the developing neural retina, where it exhibits both a steep high-ventral-to-low-dorsal gradient and a shallower high-nasal-to-low-temporal gradient (Fig. 1D; Mui et al. 2002). These sharply segregated E13.5 patterns 
Mui et al.

Figure 1. (A) Schematic dorsal-ventral (DV) section of the mouse neuroepithelium as it bulges out from the ventral diencephalon at E9.5 to form the optic vesicle. Sonic hedgehog (Shh), expressed at the ventral midline, has patterned this tissue along the DV axis by this time, such that structures closest to Shh are most ventral. pvOS, pNR, pRPE, and pdOS are presumptive ventral optic stalk (red), neural retina (green), retinal pigment epithelium (yellow), and dorsal optic stalk (gray), respectively. Graded expression of the Vax1 and Vax2 genes within these tissue anlagen is indicated. $(B)$ A schematic DV section similar to that in $A$, at $\mathrm{E} 10.5$, after the optic vesicle has invaginated to form the optic cup. $(C-F) \operatorname{Vax} 1(C), \operatorname{Vax} 2(D)$, Pax2 $(E)$, and Pax6 (F) mRNA in the developing eye at E13.5 as revealed by in situ hybridization. Vax1 and Pax2 mRNAs are both confined to the optic stalk (OS) and optic disk (OD), and are excluded from the neural retina (NR). In contrast, Vax2 and Pax6 mRNAs are confined to the retina at this same time, with $\operatorname{Vax} 2$ exhibiting a high-ventral-to-low-dorsal expression
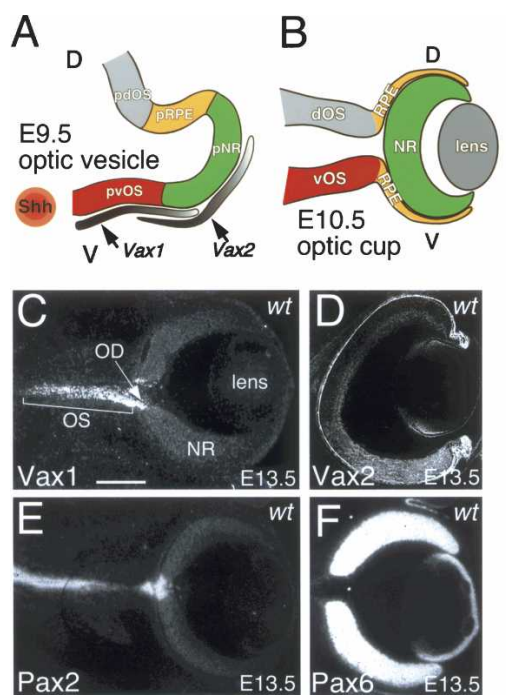
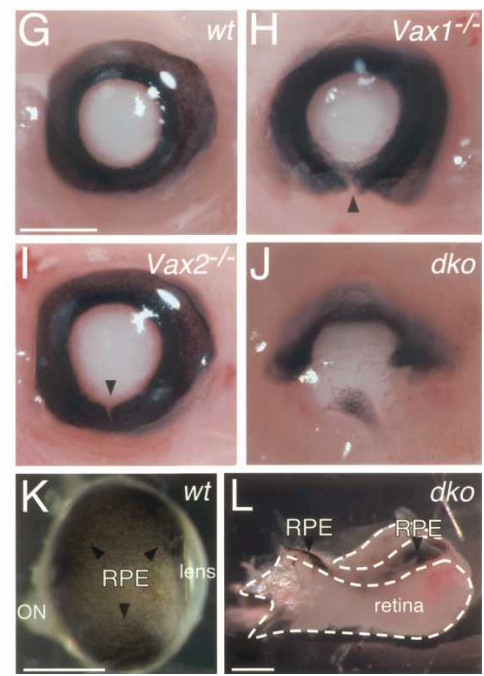

gradient $(D)$. $(G-I)$ Whole-mount images of wild-type, Vax single-mutant, and Vax double-mutant embryos at E13.5. The Vax1 and Vax2 genes exhibit strong genetic interaction, as revealed by the presence of coloboma in single and double mouse mutants. The pigmented RPE completely encompasses the eye in wild-type (wt) E13.5 embryos $(G)$, but all Vax1 mutant embryos display a coloboma (arrowhead) in the ventral retina at this same time $(H)$. A subset of Vax2 mutants exhibit a very small coloboma at E13.5 (I), but all double mutants (dko) carry an extreme coloboma that occludes RPE from the ventral half of the eye $(J)$. $(K, L)$ Whole eyes in wild-type and double mutants, respectively, at birth $(\mathrm{PO}) .(L)$ During late embryogenesis, proliferation of ectopic retina in the double mutants is so pronounced (see below) that by P0, RPE is found only in a small strip of dorsal tissue that extends to the midline of the brain. (K) RPE surrounds the wild-type eye up to its junction with the optic nerve (ON). Bars in $C$ (for $C-F$ ), $G$ (for $G-J$ ), $K$, and $L$ all represent $100 \mu \mathrm{m}$.

of expression for Vax1 and Vax2 are similar to those seen at the same time for mRNAs encoding the paired homeodomain transcription factors Pax2 (Fig. 1E) and Pax6 (Fig. 1F), respectively. We were therefore surprised to observe a strong genetic interaction between Vax1 and Vax2 in mice in which both genes are inactivated. This interaction is apparent at multiple levels, but is initially most obvious in the appearance of retinal coloboma, a failure of the optic fissure to close ventrally and form the optic disk, the boundary between the optic nerve and the retina (Fig. 1G-J). Coloboma is not observed in E13.5 wild-type embryos (Fig. 1G), is fully penetrant, but of moderate severity in $\operatorname{Vax}^{-1-}$ mutants (Fig. $1 \mathrm{H}$ ), and is both rare in occurrence and mild in $\mathrm{Vax}^{-/-}$mice (Fig. 1I). In marked contrast, it is fully penetrant and notably severe in $\operatorname{Vax}^{-/-} \mathrm{Vax}^{-/-}$double mutants (Fig. 1J). By the time of birth, the double mutants display a grotesquely configured eye, in which the boundary between retina and optic nerve is absent, and both retinal pigment epithelium (RPE) and neural retina (NR) are found throughout the territory of the optic nerve (Fig. 1K,L).

\section{Vax genes act at the midpoint of mouse embryogenesis}

Most of the previously described mouse Vax1 and Vax2 single-mutant phenotypes have been analyzed from late embryogenesis through the first two post-natal weeks (Bertuzzi et al. 1999; Hallonet et al. 1999; Barbieri et al. 2002; Mui et al. 2002). However, we find that these phenotypes actually reflect Vax gene activity during a much earlier, relatively narrow window of time, from approximately E9.5 to E11.5, when the two genes are, in fact, coexpressed. During this time, mouse Vax1 extends from the ventral optic stalk into the ventral retina, and conversely, mouse Vax2 extends from the ventral retina into the ventral optic stalk (Ohsaki et al. 1999). At E9.5, the developing eye has progressed to the optic vesicle stage, and has already been patterned along the dorsalventral axis through the action of sonic hedgehog (Figs. $1 \mathrm{~A}, 2 \mathrm{~A})$. Invagination of the optic vesicle occurs over the ensuing day, and leads to the formation of the optic cup by E10. 5 (Figs. 1B, 2B). At this stage, the diminishing expression of Vax1 mRNA in the ventral retina is also graded along the nasal-temporal axis-from high in the ventral nasal retina to low in the ventral temporal retina (Fig. 2D-F). This Vax1 gradient is therefore similar to the high-nasal-to-low-temporal gradient of Vax2 mRNA in the ventral retina, which, unlike $\operatorname{Vax} 1$, persists into late embryogenesis (Mui et al. 2002). By E11.5, the general configuration of what will be the mature eye is apparent, with the RPE having extended ventrally to surround the eye, and the entirety of the $\operatorname{Vax} 1^{+}$ventral optic stalk having invaginated into the interior of the developing optic nerve (Fig. 2C). The evolving Vax1 and Vax2 expression patterns from E9.5 to E11.5 are schematized in Figure 2G and I.

The importance of the overlapping expression of $\operatorname{Vax} 1$ and Vax2 from E9.5 to E11.5 is revealed by the appearance of double-mutant phenotypes, which first develop at this time, and are evident in an increasingly pronounced alteration in Pax gene expression (Fig. 3). At 

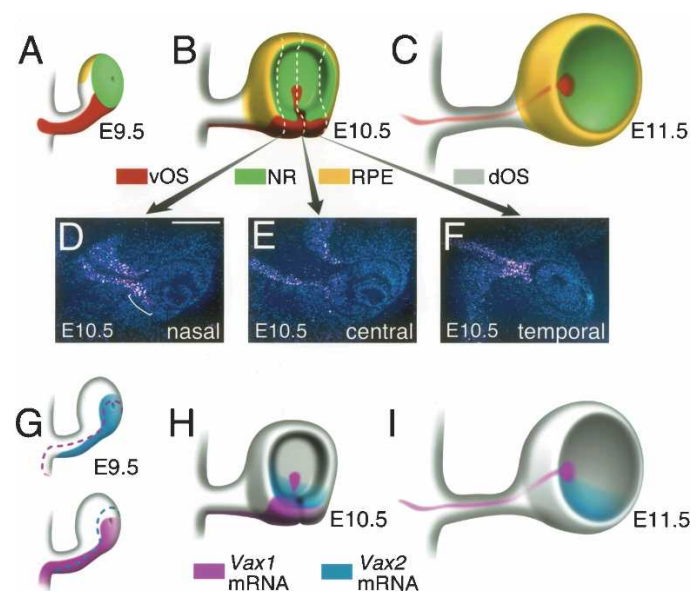

Figure 2. Overlapping expression of the $\operatorname{Vax} 1$ and $\operatorname{Vax} 2$ genes from E9.5 to E11.5. $(A-C)$ Schematic three-dimensional view of eye development at E9.5, E10.5, and E11.5 in the mouse (lens not shown). Red, green, yellow, and gray regions of the neuroepithelium indicate ventral optic stalk, neural retina, RPE, and dorsal optic stalk, respectively. $(D-F)$ Three DV sections-nasal $(D)$, central $(E)$, and temporal $(F)$-of the E10.5 optic vesicle, hybridized with a Vax1 probe. Vax1 mRNA is apparent in the optic stalk throughout, and in the ventral nasal (bracketed in $D$ ) but not ventral temporal E10.5 retina. $(G-I)$ Schematic representation of the expression domains of the mRNAs encoding Vax1 (purple) and Vax2 (blue), at E9.5. E10.5, and E11.5. Expression of the two genes is extensively overlapping at E9.5, less so at E10.5, and very much less so at E11.5. By E12.5, the expression of Vax1 and Vax2 no longer overlaps. Bar in $D$ (for $D-F$ ) represents $300 \mu \mathrm{m}$.

E10, when invagination of the optic vesicle has just begun, the Pax2 and Pax6 expression domains in the double mutants (Fig. 3B,D, respectively) are similar to those seen in wild type (Fig. 3A,C), although Pax2 expression in the ventral optic stalk (brackets in Fig. 3A-D) is reduced relative to wild type (Fig. $3 \mathrm{~A}, \mathrm{~B}$ ), while Pax6 expression is increased (Fig. 3C,D). By E11.5 in wild-type embryos, the Pax2 and Pax6 proteins have nearly assumed their mature expression profiles-Pax6 in the retina and Pax 2 in the optic stalk-with a modest number of $\mathrm{Pax}^{+}$cells remaining in the ventral retina (Fig. $3 \mathrm{E})$. At this same time, in the double mutants, however, nearly all of the ventral neuroepithelium is noticeably thickened, and nearly all of the cells of this thickened epithelium are both $\mathrm{Pax}^{-}$and $\mathrm{Pax}^{+}$(Fig. 3F). The expansion of the ventral neuroepithelium (arrowheads in Fig. 3E,F), which is apparent even at E10 (Fig. 3A-D), prevents the normal ventralward extension of the RPE, and precludes closure of the optic disk. The RPE is largely confined to the dorsal aspect of the optic vesicle (Fig. 1J).

The thickened ventral region corresponds to the area of the neuroepithelium where Vax1 and Vax2 normally overlap in their expression from E9.5 to E11.5 (Fig. 2G-I; Ohsaki et al. 1999). It is marked by the pronounced upregulation of proliferation, as assessed by a 2-h pulse of BrdU (Fig. 3G,H). This level of proliferation is aberrant for the astrocyte precursors of the optic stalk (boxed area in Fig. 3G), but is normal for RPCs. At E12.5, the development of ventral retinal tissue extends all the way to the midline of the CNS-through what would be the ventral optic stalk in wild-type embryos - and all of these transformed cells now express Pax6 mRNA (Fig. 3Q,R).

In contrast to the exuberant proliferation of neural retinal tissue, RPE differentiation is sharply limited in the Vax double mutants. Dopachrome tautomerase (Dct) mRNA, which encodes an enzyme required for melanin production in the RPE, is entirely confined to the dorsal aspect of the E12.5 optic cup (Fig. 3I,J). Similarly, Mitf (Microphthalmia-associated Transcription Factor), a protein that is associated with the onset and maintenance of pigmentation (Nakayama et al. 1998; Nguyen and Arnheiter 2000) and the early specification of the RPE (Bumsted and Barnstable 2000), is markedly reduced on the ventral side of the E11.5 optic cup of the double mutants and is absent by E12.5 (data not shown).

This morphological transformation of the developing optic stalk at the midpoint of mouse embryogenesis in the Vax double mutants is histologically similar to that seen in zebrafish embryos that have been exposed to Vax antisense morpholinos (Take-uchi et al. 2003). Although this antisense study focused on the morphogens that regulate Vax expression, and therefore did not include an examination of the battery of candidate target genes that we have analyzed, the histological appearance of the optic neuroepithelium in the morpholino-treated embryos nonetheless parallels that of the Vax1/2 double mutants. The optic-stalk-to-retina transformation appears to be less extensive in the fish, but this may be attributed to the incomplete inactivation of the Vax genes by the morpholinos (Take-uchi et al. 2003). Thus, Vax control of mid-embryonic eye development, at least with respect to tissue morphogenesis, appears to be conserved between fish and mammals.

Ectopic induction of the transcription factor repertoire of RPCS

We find that the mid-embryonic transformation of optic stalk morphology is also accompanied by a marked alteration in the expression of genes that are normally controlled by Pax2 and Pax6. By E12.5, cells in the ectopic retinal tissue of the ventral optic cup of the Vax double mutants have begun to express the full panoply of basic helix-loop-helix (bHLH) transcription factors that are activated by Pax6, and that are required for retinal neurogenesis and the differentiation of specific neuronal cell types (Reh and Levine 1998; Cepko 1999). These include Math5 (Fig. 3M,N), Neurog2 (data not shown), and Neurod1 (Fig. 3O,P), which are required for the differentiation of retinal ganglion cells, photoreceptors, and amacrine cells, respectively (Perron et al. 1999; Wang et al. 2001; Inoue et al. 2002). None of these proteins are normally expressed in the optic stalk (Fig. 3M,O). Although it develops from a ventral anlage, the ectopic retina-like tissue that expresses these bHLH proteins nonetheless retains the ability to express dorsal retinal markers such as Tbx5 (Fig. 3K,L; Koshiba-Takeuchi et al. 2000). 
Mui et al.

Figure 3. Histological and molecular transformation of optic stalk into retina in the Vax double mutants. $(A, B)$ Pax2 mRNA (brown reaction product) in the optic vesicle as it invaginates to form the optic cup, in wild-type (wt; $A)$ and Vax1/ Vax2 double knockouts (dko; $B$ ). Dorsal is top, and midline is left. Pax2 mRNA is expressed in the ventral optic stalk (vOS; bracketed), but its expression levels are slightly reduced in the double mutants, which display a thickened vOS. $(C, D)$ Pax6 mRNA (brown reaction product) at the same time, in wild-type $\left(\mathrm{wt}_{;} C\right)$ and Vax1/Vax2 double knockouts (dko; D). Pax6 mRNA is expressed in the vOS (bracketed), but its expression levels are slightly elevated in the thickened vOS of the double mutants. (E,F) Pax2 (green) and Pax6 (red) protein expression in the nuclei of neuroepithelial cells of the E11.5 optic cup, as detected immunohistochemically in wild-type $(\mathrm{wt}, E)$ and $\operatorname{Vax} 1 / \mathrm{Vax} 2$ double knockout $(\mathrm{dko} F)$ embryos. $(G, H) \mathrm{BrdU}^{+}$ nuclei of proliferative cells (light-blue signal), labeled with a 2-h pulse of BrdU, detected immunohistochemically in DV sections of wild-type $(G)$ and double-mutant (H) E12.5 embryos. Developing optic tissue is outlined. A segment of what should
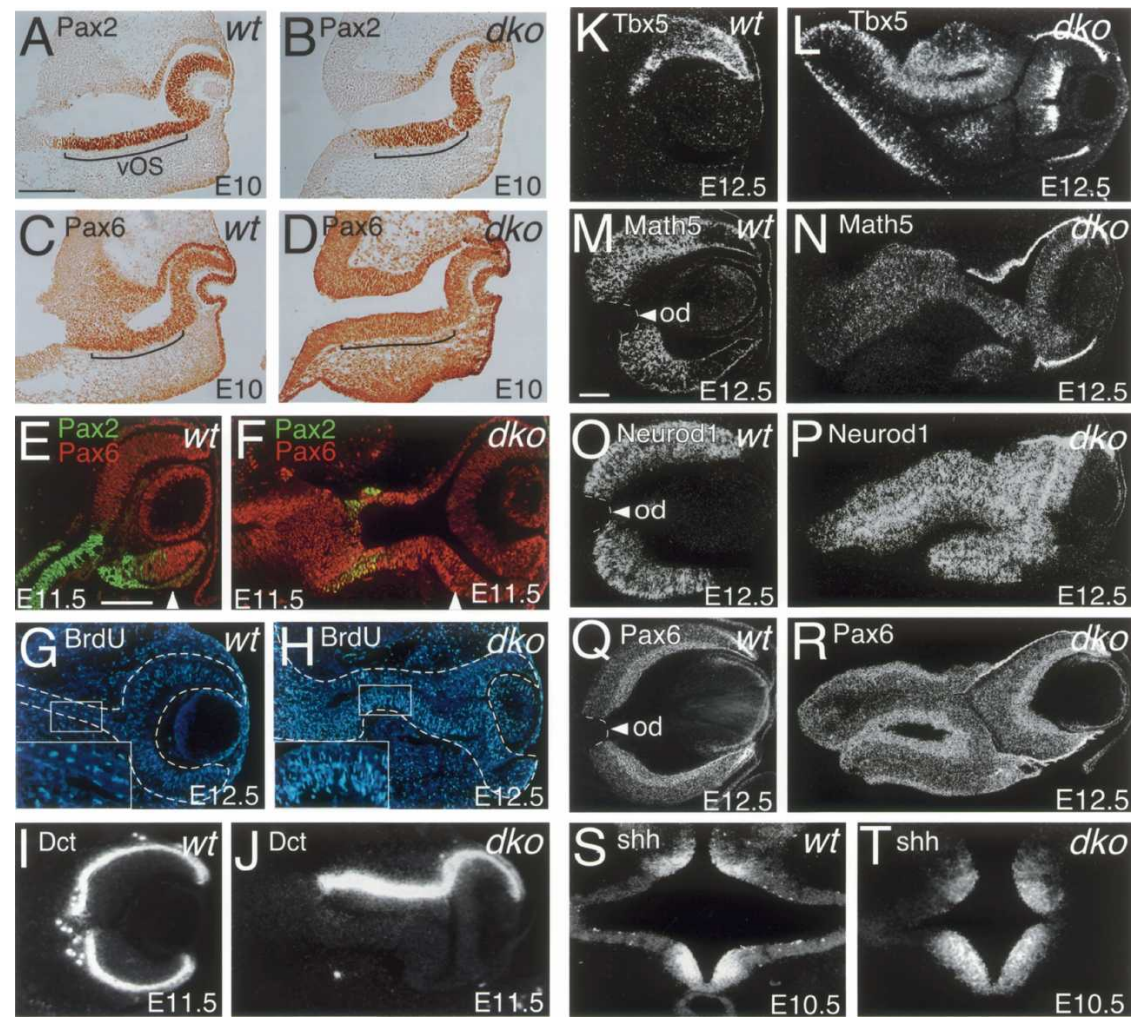

be the vOS (boxed) is enlarged $2.5 \times$ in the insets. This segment contains a modest number of dividing cells in wild-type, but many more dividing cells in the double mutants. $(I, J)$ Expression of Dopachrome tautomerase (Dct) mRNA, a marker of the RPE, as assessed by in situ hybridization (dark-field image) in DV sections of E12.5 wild-type $(I)$ and Vax double-mutant $(J)$ embryos. Dct expression is completely excluded from the ventral optic cup in the double mutants. $(K, L)$ Expression of mRNA encoding the transcription factor Tbx5, a marker of the dorsal neural retina, in wild-type $(K)$ and double mutants $(L)$ at E12.5. $(M, N)$ Expression of mRNA encoding the neurogenic bHLH protein Math5 in wild-type $(M)$ and double-mutant $(N)$ embryos at E12.5. The optic disk (od, arrowhead) and optic stalk in wild-type are Math5 ${ }^{-}(M)$, whereas much of the ectopic tissue produced in the double mutants is Math5 ${ }^{+}(N) \cdot(O, P)$ Expression of Neurod1 $(N e u r o D)$ mRNA in wild-type $(O)$ and double-mutant $(P)$ embryos at E12.5. The optic disk and optic stalk in wild-type are Neurod1- $(O)$, whereas much of the ectopic tissue produced in the double mutants is Neurod1 ${ }^{+}(P) .(Q, R)$ Expression of Pax6 mRNA in wild-type $(Q)$ and double-mutant $(R)$ embryos at E12.5. All of the ectopic tissue produced in the double mutants is $\operatorname{Pax}^{+}(R)$. $(S, T)$ Expression of sonic hedgehog (Shh) mRNA in DV sections of wild-type $(S)$ and $\operatorname{Vax}$ double-mutant $(T)$ embryos at E10.5. Shh expression at both the telencephalic (top signal) and diencephalic (bottom signal) ventral midline is unaltered in the Vax double mutants. Bars in $A$ (for $A-D, I-L, S, T), E($ for $E, F)$, and $M($ for $M-R)$ all represent $150 \mu \mathrm{m}$.

The rapid loss of ventral optic-stalk identity in the double mutants is not due to the loss of the primary ventralizing morphogen; sonic hedgehog levels remain high at the ventral midline in the double mutants (Fig. 3S,T), in contrast to the situation in Foxg1 (BF1) mutants, where a portion of midline Shh expression is lost (Huh et al. 1999). This maintained expression of Shh is in keeping with the demonstration that the zebrafish $\operatorname{Vax}$ genes are downstream of Shh signaling and subject to Shh induction (Take-uchi et al. 2003).

\section{Development of giant retinae}

By late embryogenesis (E18.5) in the double mutants, the region that would normally be occupied by the optic nerve (Fig. 4A), is instead entirely replaced by doubledover retinal tissue, which extends all the way to the mid- line of the brain (Figs. 1L, 4B,C). In wild-type mice, RGC axons, which express the cell adhesion protein L1 (brown signal in Fig. 4A), are present in well-formed optic nerves, and cross the midline at the optic chiasm, near the ventral hypothalamus and behind the nasal turbinates. These optic nerve features are absent from the E18.5 double mutants. Instead, RGC axons run in two parallel streams that correspond to the inner surface of a duplicated (doubled-over) RGC layer, above which RGC axons normally course in the retina (Fig. 4B,C [black arrowheads in inset]), and these axons fail to cross the midline to form an optic chiasm (asterisk, Fig. 4B). This failure in midline crossing is a Vax1 mutant phenotype (Bertuzzi et al. 1999; Hallonet et al. 1999), and is due to the loss of netrin-1 in the ventral midline cells that are normally Vax $1^{+}$(Bertuzzi et al. 1999). It is much more dramatic in the double mutants, because there is much more retina-and therefore many more RGCs and RGC 


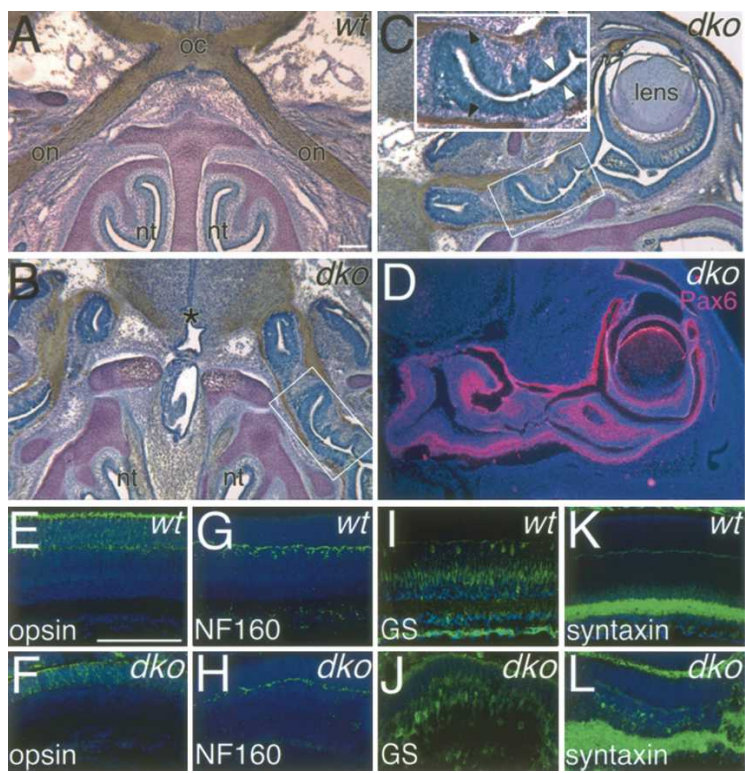

Figure 4. Complete transformation of optic nerve into retina in Vax double mutants. (A) DV section through the region of the optic nerves (on) and optic chiasm (oc) in a wild-type embryo at E18.5. The section has been stained with hematoxylin and eosin, and RGC axons have been immunostained with an antibody to the cell adhesion molecule L1 (brown reaction product). The optic nerves from the two eyes enter the base of the brain behind the nasal turbinates (nt) and cross the midline at the optic chiasm. (B) A section equivalent to that of $A$, but in the Vax double mutants. The optic nerves are replaced by doubledover retina, a segment of which is boxed. Two tracts of RGC axons run along the RGC layer of the doubled-over retina, all the way to the base of the brain, where they pile up and fail to cross the midline (asterisk) or form an optic chiasm. (C) Continuation of the section in $B$, toward the left eye and lens. The boxed area is the same as that in $B$. (Inset) Enlargement of this segment illustrates the inverted and doubled-over retina. Duplicated RGC axon fiber tracts (black arrowheads) run along the inner surface of the RGC layers. The duplicated RPE layers (white arrowheads) face one another. $(D)$ A section similar to that in $C$, hybridized with a probe to detect Pax6 mRNA (pink signal). (E,F) Retinal sections at P7 immunostained for opsin, a photoreceptor marker, in wild-type $(E)$ and double-mutant $(F)$ retinae. $(G, H) \mathrm{P} 7$ retinal sections immunostained for neurofilament 160 (NF160), a horizontal cell marker, in wild-type $(G)$ and double-mutant $(H)$ retinae. $(I, /)$ P7 retinal sections immunostained for glutamine synthase (GS), a Müller glial cell marker, in wild-type $(I)$ and double-mutant $(J)$ retinae. $(K, L)$ P7 retinal sections immunostained for syntaxin, a marker of synapses within the inner plexiform layer, in wild-type $(K)$ and doublemutant $(L)$ retinae. Bars in $A$ (for $A-D$ ) and $E$ (for $E-L$ ) represent $100 \mu \mathrm{m}$.

axons-in these mice than in the Vax1 single mutants. At this point in retinogenesis (E18.5), Pax6 expression normally becomes restricted to the RGC layer and the lower neuroblast layer, and this is also the case for the ectopic retina of the double mutants (Fig. 4D).

Most double mutants die at birth due to a cleft palate (asterisk in Fig. 4B), which is also a consequence of the loss of Vax1 (Bertuzzi et al. 1999). However, in a small fraction of the double-mutant mice $(\sim 6 \%)$, the palatal shelves partially fuse, and these mice remain viable for up to 3 wk after birth. We examined retinal cell-type specification at post-natal day $7(\mathrm{P} 7)$ in these rare doublemutant individuals, since the mouse retina is not fully developed and laminated, with its full spectrum of cell types, until the end of the first post-natal week. Although the ectopic retina was always distorted and doubled over in the P7 double mutants /due to the impossibility of accommodating the very large amount of new retina within the very small confines of what should be the optic nerve), all major subgroups of retinal cell types, as assayed by the immunolocalization of marker genes, were nonetheless present in their normal location and lamination. These include photoreceptors, as visualized by rhodopsin (Fig. 4E,F), horizontal cells as visualized by neurofilament (NF)160 (Fig. 4G,H), and Müller glia as visualized by glutamine synthetase (Fig. 4I,J). A prominent lamination of synapses, as marked by syntaxin, is evident in the inner plexiform layer of both wild-type and double-mutant neonates (Fig. $4 \mathrm{~K}, \mathrm{~L})$. Thus, the optic stalk precursors of the double mutants are converted to RPCs that are capable of generating a well-differentiated and normally laminated postnatal retina.

\section{Vax regulation of eye specification via Pax6}

How is this conversion achieved? The complete transformation of the presumptive optic stalk that we observe upon the loss of Vax1 and Vax2 indicates that these transcription factors normally act in concert to inhibit retinal specification. Among the most prominent drivers of retinal development, in both vertebrates and invertebrates, is the transcription factor Pax6. Loss-of-function mutations in the Pax6 gene lead to the loss or reduction of retinal tissue, as for the eyeless mutant in Drosophila (Quiring et al. 1994), the small eye mutant in mice (Hill et al. 1991), and aniridia in man (Jordan et al. 1992). And conversely, gain-of-function misexpression of Pax6 in a competent epithelium in both flies and vertebrates often leads to the production of ectopic eyes (Halder et al. 1995a,b; Chow et al. 1999).

Given that Pax6 is rapidly acquired and Pax2 is rapidly lost from the optic stalk in the double mutants (Fig. 3AF), we looked for evidence of direct regulation of $\mathrm{Pax} 6$ gene expression by Vax1 and Vax2. Multiple cis-regulatory elements govern Pax6 gene transcription (Fig. 5A), but early retinal expression of this gene is largely controlled by an enhancer element-designated the $\alpha$-enhancer-which is located between exons 4 and 5 (Fig. 5A; Plaza et al. 1995; Kammandel et al. 1999; Marquardt et al. 2001). This enhancer contains binding sites for several transcription factors, including an autostimulatory Pax6 site and an inhibitory Pax2 site (Fig. 5A; Kammandel et al. 1999). Of particular importance to $\alpha$-enhancer activity is an AT-rich region, designated DF4, which is immediately downstream of the Pax2/6-binding site apposed to the adjoining DF3 region (Fig. 5A; Plaza et al. 1995; Schwartz et al. 2000). This AT-rich sequence in 
Figure 5. Vax binding to the Pax6 gene. $(A)$ Schematic structure of the mouse Pax6 gene. Exons are numbered, and the positions of two alternative transcription start sites $(\mathrm{P} 0, \mathrm{P} 1)$ and the initiator codon (ATG) are indicated. Two enhancer elements important for Pax6 expression in the eye are indicated as follows: the ectodermal enhancer (ec; green boxes), whose 3 ' end contains elements critical for Pax6 expression in the lens, and the retinal $\alpha$-enhancer $(\alpha$; red boxes), which is located between exons 4 and 5, and which drives Pax6 expression in the neural retina. Bottom line displays the nucleotide sequence of the central region of the $\alpha$-enhancer, with a previously identified Pax2-binding site (blue) and a putative Vax-binding site (red) in the DF4 region. (Middle line) The arrowed fp and rp sites in the expanded boxes for the lens and $\alpha$-enhancers represent the positions of the forward and reverse primers, respectively, that were used for the PCR reactions of ChIPs. $(B)$ ChIP of the Pax6 $\alpha$-enhancer using Vax antibodies (see Materials and Methods). Chromatin from E10 heads from wild-type (wt), Vax1 ${ }^{-/-}$, $\mathrm{Vax}^{-/-}$, and $\mathrm{Vax}^{-/-} \mathrm{Vax}^{-/-}$mice was immunoprecipated with preimmune rabbit IgG, Vax1, Vax2, Pax2, or Pax6 antibody, and then analyzed for precipitation of $\alpha$-enhancer and lens-enhancer DNA sequences by PCR (see Materials and Methods). The positions of the PCR primers within the lens enhancer (fpl and $\mathrm{rp} 1$ ) and the $\alpha$-enhancer (fp2 and $\mathrm{rp} 2$ ) are indicated on the middle line in A. (Right panels) PCR bands of the appropriate size and sequence are detected for each ChIP PCR reaction that includes the putative Vax and Pax2/6-binding site of the Pax6 $\alpha$-enhancer (fp2/rp2). (Right panels) The Pax6 $\alpha$-enhancer was not detected in Vax1 or Vax2 ChIP DNA fragments from Vax double knock-outs, and Vax1 and Vax2 binding to the $\alpha$-enhancer could not be detected in ChIPs performed from Vax1 and Vax2 mutants, respectively. (Left panels) No E10 Vax1, Vax2, or Pax2 ChIP products were detected with primers amplifying lens-enhancer sequences (fp1/rp1), whereas immunoprecipitation of these lens-enhancer sequences was readily detected with the Pax6 antibody. Preimmune rabbit IgG did not yield PCR bands for either the lens or the $\alpha$-enhancer in any of the four genotypes tested. Chromosomal DNA of unfixed E10 embryonic heads was used for the PCR input lanes. (C) Electromobility shift assays (EMSAs) demonstrating in vitro binding of Vax1 and Vax2 proteins to the Vax site depicted in A. EMSAs were performed with HA-tagged versions of Vax1 and Vax2 that were in vitro translated using reticulocyte lysates (Promega). Incubations with various wild-type and mutated DNA probes corresponding to the Vax-binding site of the $\alpha$-enhancer DF4 region were performed as described in Materials and Methods. (Lanes 4,7,11,14) Both Vax1 and Vax2 (which carry identical homeodomains) shift the wild-type probe. Vax binding is not inhibited by preimmune IgG (lanes 5,8), but is inhibited by a monoclonal antibody against the HA tag (lanes 6,9). Vax1 and Vax2 binding are also competitively inhibited by 100 -fold excess wild-type probe (lanes 12,15), but not by mutated probe (lanes 13,16$)$.

DF4 binds a complex of (incompletely characterized) retinal proteins, and has been shown to be essential for $\alpha$-enhancer activity (Plaza et al. 1995; Schwartz et al. 2000). It carries a putative Vax-binding site (J.W. Kim and G. Lemke, unpubl.) with a consensus homeodomain recognition motif (red sequence in Fig. 5A).

We first performed chromatin immunoprecipitations (ChIPs), using Vax1- and Vax2-specific antibodies that we have generated, and Vax-associated chromatin templates isolated from E10 embryonic mouse heads (Fig. $5 \mathrm{~B}$; see Materials and Methods). We performed these anti-Vax ChIP experiments in wild-type, $\operatorname{Vax}^{-{ }^{--}}, \mathrm{Vax}^{-{ }^{--}}$, and double-mutant embryos, and we also used anti-Pax2, anti-Pax-6, and nonimmune rabbit IgG for separate IPs. We used PCR primers to probe for endogenous transcription-factor binding both to the DF3/DF4 regions of the Pax6 retinal $\alpha$-enhancer (primers fp2/rp2 in Fig. 5A,B), and also to the Pax6 lens enhancer (primers fp1/rp1). This latter element is located $5^{\prime}$ of the upstream (PO) Pax6 transcription start site (Fig. 5A), contains a Pax6 autoregulatory site that is required for expression of Pax6 in the lens (Kammandel et al. 1999; Aota et al. 2003), and is not obviously regulated by either Vax1 or Vax2. We were consistently able to identify and sequence verify the Pax6 $\alpha$-enhancer in DNA recovered from anti-Vax1 ChIPs and then amplified by PCR with the fp2/rp2-flanking primers, using chromatin templates prepared from wild-type and $\mathrm{Vax}^{-/-} \mathrm{E} 10$ heads, but not from $\mathrm{Vax} 1^{-/-}$ or double-mutant embryos (Fig. 5B, right). Similarly, we were able to detect Vax2 binding to this same retinal enhancer in ChIPs performed using chromatin from wild-type and $\operatorname{Vax}^{1^{-/-}}$embryos, but not from $\operatorname{Vax}^{-/-}$or double-mutant embryos. Using chromatin from E10 heads, a time at which both Pax2 and Pax6 are still wellexpressed in the double mutants (Fig. 3B,D), we were able to detect binding of both of these transcription factors to the $\alpha$-enhancer in all four genotypes. Conversely, we were unable to detect the binding of either Vaxl, Vax2, Pax2, or Pax6 in mice of any genotype, to either the $\alpha$ - or the lens-enhancer, in ChIPs performed with the same chromatin templates, but using nonimmune (rabbit IgG) controls (Fig. 5B). We did not detect Vax1, Vax2, or Pax2 binding to the $5^{\prime}$ lens-specific enhancer of the Pax6 gene using these same templates and methods with the fp1/rp1 PCR primer set, but did detect Pax6 binding (Fig. 5B, left panels). Together, these results demonstrate 
that Vax1 and Vax2 are specifically bound to the Pax6 $\alpha$-enhancer in neuroepithelial cells of the E10 forebrain in vivo.

We next carried out a series of electromobility gel shift assays (EMSA) with hemaggultinin(HA)-tagged Vax1 and Vax2 proteins, prepared by coupled in vitro transcription and translation, and then incubated with a doublestranded DNA probe containing the AT-rich DF4 sequence of the $\alpha$-enhancer that carries the putative Vaxbinding site (Fig. 5C; see Materials and Methods). Both Vax1 and Vax2, which have identical homeodomains, specifically shift this probe (Fig. 5C, lanes 4,11,7,14, respectively). This mobility shift is competitively and specifically blocked both by excess wild-type but not mutated probe (Fig. 5C, lanes 12,13,15,16, respectively), and by incubation with an anti-HA monoclonal antibody but not by preimmune IgG (Fig. 5C, lanes 5,6,8,9, respectively).

We then performed a series of cotransfection experiments (Fig. 6A), using a panel of Vax1, Vax2, Pax2, and Pax6 expression constructs and an $\alpha$-enhancer-driven $\beta$-galactosidase reporter (Kammandel et al. 1999), cotransfected into both $293 \mathrm{~T}$ and COS7 cells. We found that reporter gene expression driven by the Pax $6 \alpha$-enhancer is, as previously described, autostimulated (approximately fourfold) by coexpression of Pax6, and inhibited three- to fourfold by coexpression of Pax2 (Fig. 6A). Consistent with its expression in the Pax6 $6^{-}$cells of the optic stalk, Vaxl also repressed transcription driven by the Pax $6 \alpha$-enhancer three- to fourfold. Vax2, whose mRNA overlaps with Pax6 in the ventral retina, exhibited more modest repression (Fig. 6A). When combined, Vax1 and Pax2 together exhibited a synergistic and extremely strong $(\sim 20$-fold $)$ repression of $\alpha$-enhancer activity (Fig. 6A), consistent with their coexpression, with the fact that these two genes act in parallel to maintain the Pax6 ${ }^{-}$cells of the optic stalk (Bertuzzi et al. 1999; Hallonet et al. 1999), and with the close proximity of the Pax2- and Vax-binding sites in the Pax $6 \alpha$-enhancer (Fig. 5A). The observation that mouse Vax1 and Vax2 exhibit repressor activity against the mouse Pax6 $\alpha$-enhancer in
COS7 and 293T cells parallels the recent demonstration that chicken Vax exhibits repressor activity against the quail Pax6 $\alpha$-enhancer upon transfection into quail neuroretina cells (Leconte et al. 2004).

Finally, we directly examined Vax regulation of Pax6 $\alpha$-enhancer activity in vivo. We generated compound mutants that are both $\operatorname{Vax}^{-/-} \operatorname{Vax}^{-/-}$and also carry an $\alpha$-enhancer-taulacZ $(\alpha-\tau l Z)$ reporter gene (Baumer et al. 2003). We then assayed $\beta$-galactosidase activity histochemically (with X-gal), in sections of the eye from E12.5 compound mutant embryos (Fig. 6B). (The $\tau \mathrm{lZ}$ reporter has $\beta$ gal fused in-frame to the microtubule-associated protein tau, and results in the incorporation of the enzyme into microtubules.) In a normal embryo, $\alpha$-enhancer activity becomes reduced and restricted after E11.5 (Marquardt et al. 2001). However, we find that the activity of this enhancer in the ectopic retinal tissue that develops in the $\operatorname{Vax}^{-/-} \mathrm{Vax}^{-/-} \alpha-\tau I Z$ mice (dotted outline in Fig. 6B) is notably robust at E12.5, and that $\beta$ gal is largely confined to the exuberant retina (Fig. 6B). Thus, the Pax 6 retinal $\alpha$-enhancer is dramatically activated in cells of the optic neuroepithelium in the absence of Vax1 and Vax2 in vivo.

\section{Discussion}

The vertebrate eye is among the most exquisitely polarized of sensory tissues, and its axial patterning-the specification of its dorsoventral and nasotemporal axes during development-is essential both to its topographic connection to the brain and to its mature function. Our results demonstrate that Vax1 and Vax2, transiently coexpressed from E9.5 to E11.5 at the junction between the optic stalk and the presumptive neural retina, are central to this process. Together, these two transcription factors cooperatively control eye-field polarization, neuroepithelial cell proliferation, and retinal differentiation.

These features of Vax function were not evident in either of the $\operatorname{Vax}$ single mutants. Optic stalk cells in Vax $1^{-/-}$mice, for example, fail to properly associate with RGC axons, and lose expression of Pax2 and acquire
A

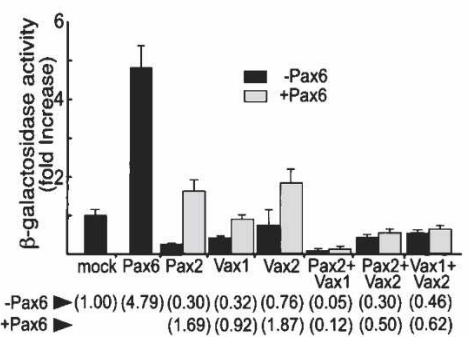

B

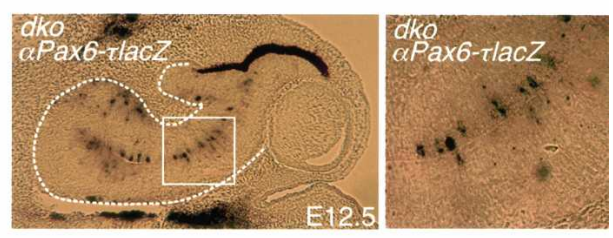

Figure 6. Vax regulation of Pax6 gene expression. (A) Vax repression of the Pax6 $\alpha$-enhancer. CMV-promoter-driven expression constructs for Vax1, Vax2, Pax2, and Pax6, in the indicated combinations, were cotransfected with a Pax6 $\alpha$-enhancer-driven $\beta$-galactosidase reporter construct, into both HEK293 cells and COS7 cells, as described in Materials and Methods. Results displayed are for 293 cells; COS7 transfections yielded very similar results. Numbers below the graph indicate fold change in $\beta$ gal activity relative to mock (empty expression vector) control, in the absence or presence of cotransfected Pax6 $(-/+$ Pax6). See text for details. (B) Activated expression of the Pax6 $\alpha$-enhancer in the ectopic retinal tissue of the Vax double knockouts (dko). $\beta$-Galactosidase activity driven by the Pax 6 -enhancer, as coupled to

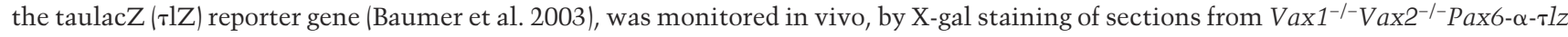
embryos. Pax6- $\alpha-\tau l z$ expression is robust in the ectopic retinal tissue that develops in these mice (dotted outline). The boxed area in the left panel is enlarged $3 \times$ at right. 
Pax6; however, they do not go on to differentiate into full-blown retina (Bertuzzi et al. 1999). Similarly, most Vax2 mutants display histologically normal retinae and optic nerves. When analyzed during the second post-natal week, $\operatorname{Vax}^{-/-}$mice exhibit a dorsalization of the ventral retina in terms of both gene expression and the projection of RGC neurons to their targets in the superior colliculus (Mui et al. 2002), but this dorsalization is progressively less severe in progressively more nasal regions of the ventral retina; and essentially no dorsalization is evident in the extreme ventral nasal retina (Mui et al. 2002). One explanation put forward for this progressively diminishing penetrance along the nasal-temporal axis was that a second gene-graded similarly to and acting in concert with Vax2-might compensate for Vax2 in the ventral nasal retina, where their combined expression was normally highest (Mui et al. 2002). Our results strongly support this possibility; they suggest that the second gene is $\operatorname{Vax} 1$, which acts not in the post-natal retina, when the $\operatorname{Vax}^{-/-}$RGC projection phenotype was analyzed, but rather at E9.5-E11.5, when the dorsoventral identity of the developing eye field is first established and consolidated (Fig. 2D-F). At the same time, our results suggest that the incomplete optic-nerve-toretina transformation seen in the $\operatorname{Vax} 1$ mutants is accounted for by the overlapping presence of Vax2 from E9.5 to E11.5. This interpretation is consistent with the morphological and cell-tracing observations of Takeuchi and colleagues (2003) in zebrafish, where application of single Vax1 or Vax2 antisense morpholinos lead to modest changes in optic-stalk structure, but combined treatment with both antisense reagents induced the appearance of tissue that resembles retina histologically.

Shh is the dominant ventralizing signal in the developing eye field as it is elsewhere in the embryonic CNS; it patterns the field through induction of the Pax2 gene proximally and the Pax6 gene distally (Ekker et al. 1995; Macdonald et al. 1995). The undiminished expression of Shh in the Vax double mutants, along with presence of Pax2 in the ventral optic stalk at E10.5, but not E12.5, together demonstrate that in the absence of Vax, Shh is sufficient for the induction, but not the maintenance of Pax2. Furthermore, the dramatic expansion of Pax6 expression all the way to the CNS midline-the source of Shh-demonstrates that the normally more distal expression of the Pax6 gene is not regulated simply by fixed lower levels of Shh. Instead, Vax1 and Vax2 act as intracellular effectors of sonic hedgehog in the developing eye field, and in their absence, neuroepithelial cells in the ventral-most structure of the field lose Pax2 and acquire Pax6, assume the identity of cells in the next most dorsal structure, and become RPCs.

Our data suggest two mechanisms for Vax action in the establishment of ventral fate. These mechanisms are not mutually exclusive, and may operate in parallel. First, although the Vax proteins are clearly not required for the initial activation of the Pax2 gene in the ventral optic stalk and retina (Fig. 3B), these proteins may nonetheless normally act to maintain expression of Pax2, which, at midgestation, acts as a transcriptional repressor of the Pax6 gene (Schwartz et al. 2000; Baumer et al. 2003). Second, our data indicate that the Vax proteins directly inhibit optic-stalk expression of Pax6, which acts as a dominant driver of retinal differentiation. The Vax and Pax2 genes are coexpressed in the ventral optic primordium, both are induced by Shh (Schulte et al. 1999; Take-uchi et al. 2003), and misexpression of chicken $V a x$ results in the expression of Pax2 (Schulte et al. 1999; Barbieri et al. 2002).

In the Vax double mutants, Pax2 expression is initiated as in wild type, but is rapidly lost, concomitant with an acquisition of Pax 6 and the subsequent activation of the retinal bHLH genes. The Vax proteins repress the Pax6 gene in vitro (Fig. 6A; Leconte et al. 2004) and in vivo (Fig. 6B), especially when coexpressed with Pax2 (Fig. 6A), and this effect is mediated at least in part by direct binding to the DF4 Vax site within the retinal enhancer of this gene (Figs. 5B,C, 6B). Our data suggest that the synergistic repression of the Pax 6 gene by Vax1 and Pax2 (Fig. 6A), which are normally coexpressed in the Pax6 $6^{-}$cells of the optic stalk, is mediated through this same $\alpha$-enhancer, since the Pax- and Vax-binding sites of the enhancer are in close proximity (Fig. 5A). Although it is definitely possible that Vax proteins bind to other regions of the Pax6 gene, our ChIP data indicate that the $5^{\prime}$ lens enhancer is not one of them (Fig. 5B), and our compound mutant ( $\beta$ gal reporter) data suggest that the $\alpha$-enhancer is a major target (Fig. 6B).

It should be noted that in vivo, the $\operatorname{Vax}$ genes in combination are far more potent than Pax2 alone with respect to repression of the retinal differentiation program that is driven by Pax6. Pax2 mutants in mice and zebrafish display an optic-nerve phenotype that is indistinguishable from the partially penetrant phenotype of the Vax1 single mutants-they do not develop exuberant retina-and $\operatorname{Vax}$ gene expression is maintained in Pax2 ${ }^{-/-}$mice (Bertuzzi et al. 1999). Furthermore, the optic nerve phenotype that develops in $\operatorname{Vax}^{-/-} \mathrm{Pax}^{-/-}$ double mutants is not obviously different from that of either single mutant (N. Baumer, pers. comm.). These observations favor a simple model in which the concerted loss of Vax1 and Vax2 leads to the abnormal expression of Pax6 in the ventral optic stalk after E11.5, which in turn leads to the repression of Pax2, and the activation of the full program of bHLH-driven retinal differentiation.

One conundrum apparent from published expression analyses (Barbieri et al. 2002; Mui et al. 2002) is that the Vax2 gene continues to be expressed in the ventral retina throughout late embryogenesis, in retinal ganglion cells that are also $\mathrm{Pax}_{6}{ }^{+}$. This would seem to be inconsistent with Vax2 functioning as a repressor of the Pax6 gene. As we will describe in detail elsewhere, this apparent inconsistency is resolved when the subcellular localization of the Vax2 protein is examined in detail during embryonic and early post-natal eye development.

Taken together, the results presented above demonstrate that the Vax proteins cooperatively ventralize the developing eye field by acting at the midpoint of mouse 
embryogenesis. They allow for the development of the optic nerve by inhibiting the development of the retina, and they achieve this through their ability to repress the Pax6 gene and the retinal differentiation programs that it normally promotes.

\section{Materials and Methods}

\section{Expression studies}

In situ hybridization with ${ }^{33} \mathrm{P}$-radiolabeled riboprobes was performed as described previously (Bertuzzi et al. 1999; Mui et al. 2002). Dissected mouse embryos were anesthetized and immersion fixed in $4 \%$ paraformaldehyde/PBS overnight at $4{ }^{\circ} \mathrm{C}$, followed by overnight infiltration with $20 \%$ sucrose. Cryoprotected tissues were then embedded in OCT medium (Miles). Hybridizations were performed with $20-\mu \mathrm{m}$ coronal sections of retina at birth (P0), P7, and with embryos at E9.5-E13.5, and at E18.5.

Immunohistochemistry was performed with cryostat sections $(20 \mu \mathrm{m})$ that were blocked with $10 \%$ normal goat serum prior to incubation with antibodies. The following antibodies were incubated overnight at $4^{\circ} \mathrm{C}$ : polyclonal mPax2 (Zymed, at 1:300), monoclonal mPax6 (DHSB, University of Iowa, at 1:10), polyclonal L1 (gift of Dr. Louis Reichardt, University of California, San Francisco, at 1:1000), monoclonal NF160 (Sigma, at 1:40), polyclonal Ph-H3 (Upstate, at 1:200), monoclonal rhodop$\sin$ (Chemicon, at 1:300), monoclonal syntaxin (Sigma, at 1:90), and polyclonal glutamine synthetase (Sigma, at 1:1000). FITCand Cy3-conjugated goat anti-rabbit and goat anti-mouse antibodies (Jackson) were used at 1:200. Peroxidase-conjugated goat anti-rabbit antibodies (Jackson) were used at 1:100. Pax2 and Pax6 sections were counterstained with p-phenylenediamine dihydrochloride (Sigma); L1 sections were counterstained with hematoxylin and eosin.

\section{Vax1 and Vax2 antibody production}

Antibodies against mouse Vax1 (accession no. NP_033527) and mouse Vax2 (accession no. NP_036042) were generated against fusion proteins composed of the N-terminal fragment of Vax1 (residues 1-72) or Vax2 (residues 1-71) fused to glutathione-Stransferase (GST) in the pGEX-4T1 vector (Pharmacia) at the BamH1/XhoI sites. Polyclonal antibodies against recombinant GST-Vax1(1-72) or GST-Vax2(1-71) proteins were produced in rabbits by intradermal injection. Antibodies recognizing these fusion proteins were purified using the QuickPrep affinity purification kit (Sterogene Bioseparations), after prior binding to a GST affinity column, and were assessed for specificity by Western blot.

\section{ChIP and PCR}

In general, we followed the methods of Weinmann et al. (2001). Briefly, nuclei were isolated from E10 mouse heads, and chromatin was sheared into 0.5-1-kb fragments. Vax1, Vax2, Pax2, or Pax6 proteins and their associated protein-DNA complexes were isolated by immunoprecipitation with rabbit anti-Vax1 antibody, rabbit anti-Vax2 antibody, rabbit anti-Pax2 antibody, mouse anti-Pax6 antibody, or preimmune rabbit IgG (Vector). DNA fragments coprecipitated with Vax1, Vax2, Pax2, or Pax6 proteins were isolated by phenol/chloroform/isoamyl alcohol extraction, and $100 \mathrm{ng}$ of these immunoprecipitated DNAs were used as templates for PCR amplification of the Pax6 lens en- hancer (fp1/rp1) or the Pax6 $\alpha$-enhancer (fp2/rp2) elements (see Fig. 5A,B). PCR was performed for 33 cycles, with $1 \mathrm{~min}$ at $94^{\circ} \mathrm{C}, 1 \mathrm{~min}$ at $55^{\circ} \mathrm{C}$, and $1 \mathrm{~min}$ at $72^{\circ} \mathrm{C}$, after denaturation for $5 \mathrm{~min}$ at $94^{\circ} \mathrm{C}$ for each cycle. PCR products were cloned into pCRII-topo (Invitrogen Inc.) for automated sequencing. PCR primers for ChIP PCR were as follows: fp1, CTAAAGTAGACA CAGCCTT; fp2, GTGACAAGGCTGCCACAAGCGCC; rp1, GGAGACATTAGCTGAATTC; rp2, CCGTGTCTAGACAGA AGCCCTCTC

\section{Electrophoretic mobility shift assays}

Double-stranded wild-type oligomers $\quad\left(5^{\prime} \rightarrow 3^{\prime}\right.$ strand, GACTTCCGCCTATTTCCAGAAATTAAGCTCAAACTTGA CGT) and mutant oligomers $\left(5^{\prime} \rightarrow 3^{\prime}\right.$ strand, GACTTCCGCC TATTTCCAGACCGGCAGCTCAAACTTGACGT) containing the DF4 sequence of the Pax6 $\alpha$-enhancer (Plaza et al. 1995; Kammandel et al. 1999) were labeled by exo(-) Klenow fragment in the presence of $\left[\alpha-{ }^{32} \mathrm{P}\right] \mathrm{dCTP} .{ }^{32} \mathrm{P}$-labeled oligomers were incubated with in vitro-translated protein samples in a binding buffer (10 mM HEPES at $\mathrm{pH} 7.7,75 \mathrm{mM} \mathrm{KCl}, 2.5 \mathrm{mM} \mathrm{MgCl}_{2}$, $0.1 \mathrm{mM}$ EDTA, $1 \mathrm{mM}$ DTT, $5 \%$ glycerol, $0.5 \%$ BSA, and 0.1 $\mathrm{mg} / \mathrm{mL}$ poly-dIdC) on ice for $30 \mathrm{~min}$. Samples were analyzed by $5 \%$ polyacrylamide gel electrophoresis and autoradiography. For competition, ${ }^{32} \mathrm{P}$-labeled oligomers were preincubated on ice for 10 min with $100 \times$ unlabeled wild-type oligomers or mutant DF4 oligomers.

\section{Reporter analyses}

The Pax6-408B/X construct of Kammandel et al. (1999) was cotransfected with pCMV-Pax6, pCMV-Pax2, pCS2(+)-MTVax1, or pCS2(+)-MT-Vax2 into $293 \mathrm{~T}$ or COS7 cells. ptk-LUC was coexpressed as a normalization control for transfection efficiency. Cells were lysed in a buffer containing $25 \mathrm{mM}$ GlyGly, $15 \mathrm{mM} \mathrm{MgSO}_{4}, 4$ mM EGTA, $1 \%$ Triton-X 100, and $1 \mathrm{mM}$ DTT, and $\beta$-galactosidase activity was assayed in luciferase equivalents of cell lysates.

\section{$X$-gal staining}

Vax $1^{+/-}$Vax $^{-/-}$mice were bred with Pax6 6 -taulacZ mice (Baumer et al. 2003) to generate $\operatorname{Vax} 1^{+/-} \operatorname{Vax}^{-/-}$Pax6- $\alpha-\tau l z^{+-}$ E12.5 embryos. These were fixed with $0.5 \%$ glutaldehyde $/ 4 \%$ paraformaldehyde in PBS for $30 \mathrm{~min}$ on ice and cryoprotected in $20 \%$ sucrose/PBS overnight at $4^{\circ} \mathrm{C}$. Sections from frozen embryos were washed three times with PBS, and stained in X-gal reaction solution: $35 \mathrm{mM}$ potassium ferrocyanide, $35 \mathrm{mM}$ potassium ferricyanide, $2 \mathrm{mM} \mathrm{MgCl}$, $0.02 \%$ Nonidet P-40 (NP40), $0.01 \%$ sodium deoxycholate, and $1 \mathrm{mg} / \mathrm{mL} \mathrm{X-gal.}$

\section{BrdU labeling}

Pregnant dams were pulsed with BrdU (100 $\mu \mathrm{g} / \mathrm{g}$ body w) injected intraperitoneally. The injection was repeated after 20 min, and the animals sacrified and embryos collected $2 \mathrm{~h}$ after the first injection. Immunohistochemistry was performed with a mouse monoclonal anti-BrdU antibody (Sigma) diluted 1:100.

\section{Acknowledgments}

We thank Drs. Peter Gruss and Nicole Baumer for the generous provision of the ${ }^{-P a x} 6-\alpha-\tau l z$ mice and for continuing discussion, Joe Hash, Patrick Burrola, and Ramil Libat for excellent technical support, and Jamie Simon for the schematic drawings of 
Figure 2. Supported by grants from the NIH (G.L.), the Telethon Foundation (S.B.) and the Italian Ministry of Research (S.B.); by a long-term fellowship from the Human Frontiers Science Program (J.W.K.); and by the Medical Scientist Training Program at University of California, San Diego (S.M.).

\section{References}

Aota, S., Nakajima, N., Sakamoto, R., Watanabe, S., Ibaraki, N., and Okazaki, K. 2003. Pax6 autoregulation mediated by direct interaction of Pax 6 protein with the head surface ectoderm-specific enhancer of the mouse Pax6 gene. Dev. Biol. 257: 1-13.

Barbieri, A., Broccoli, V., Bovolenta, P., Alfano, G., Marchitiello, A., Mocchetti, C., Crippa, L., Bulfone, A., Marigo, V., Ballabio, A., et al. 2002. Vax2 inactivation in mouse determines alteration of the eye dorsal-ventral axis, misrouting the optic fibers and eye coloboma. Development 129: 805-813.

Baumer, N., Marquardt, T., Stoykova, A., Spieler, D., Treichel, D., Ashery-Padan, R., and Gruss, P. 2003. Retinal pigmented epithelium determination requires the redundant activities of Pax2 and Pax6. Development 130: 2903-2915.

Bertuzzi, S., Hindges, R., Mui, S.H., O'Leary, D.D.M., and Lemke, G. 1999. The homeodomain protein Vax1 is required for axon guidance and major tract formation in the developing forebrain. Genes \& Dev. 13: 3092-3105.

Bumsted, K.M. and Barnstable, C.J. 2000. Dorsal retinal pigment epithelium differentiates as neural retina in the microphthalmia (mi/mi) mouse. Invest. Ophthalmol. Vis. Sci. 41: 903-908.

Cepko, C.L. 1999. The roles of intrinsic and extrinsic cues and bHLH genes in the determination of retinal cell fates. Curr. Opin. Neurobiol. 9: 37-46.

Chiang, C., Litingtung, Y., Lee, E., Young, K.E., Corden, J.L., Westphal, H., and Beachy, P.A. 1996. Cyclopia and defective axial patterning in mice lacking Sonic hedgehog gene function. Nature 383: 407-413.

Chow, R.L. and Lang, R.L. 2001. Early eye developement in vertebrates. Ann. Rev. Cell. Dev. Biol. 17: 255-296.

Chow, R.L., Altmann, C.R., Lang, R.A., and Hemmati-Brivanlou, A. 1999. Pax6 induces ectopic eyes in a vertebrate. Development 126: 4213-4222.

Ekker, S.C., Ungar, A.R., Greenstein, P., von Kessler, D.P., Porter, J.A., Moon, R.T., and Beachy, P.A. 1995. Patterning activities of vertebrate hedgehog proteins in the developing eye and brain. Curr. Biol. 5: 944-955.

Halder, G., Callaerts, P., and Gehring, W.J. 1995a. Induction of ectopic eyes by targeted expression of the eyeless gene in Drosophila. Science 267: 1788-1792.

- 1995b. New perspectives on eye evolution. Curr. Opin. Genet. Dev. 5: 602-609.

Hallonet, M., Hollemann, T., Pieler, T., and Gruss, P. 1999. Vax1, a novel homeobox-containing gene, directs development of the basal forebrain and visual system. Genes \& Dev. 13: $3106-3114$.

Hill, R.E., Favor, J., Hogan, B.L., Ton, C.C., Saunders, G.F., Hanson, I.M., Prosser, J., Jordan, T., Hastie, N.D., and van Heyningen, V. 1991. Mouse small eye results from mutations in a paired-like homeobox-containing gene. Nature 354: 522 525.

Huh, S., Hatini, V., Marcus, R.C., Li, S.C., and Lai, E. 1999. Dorsal-ventral patterning defects in the eye of BF-1-deficient mice associated with a restricted loss of Shh expression. Dev. Biol. 211: 53-63.
Inoue, T., Hojo, M., Bessho, Y., Tano, Y., Lee, J.E., and Kageyama, R. 2002. Math3 and NeuroD regulate amacrine cell fate specification in the retina. Development 129: 831842 .

Jordan, T., Hanson, I., Zaletayev, D., Hodgson, S., Prosser, J., Seawright, A., Hastie, N., and van Heyningen, V. 1992. The human PAX6 gene is mutated in two patients with aniridia. Nat. Genet. 1: 328-332.

Kammandel, B., Chowdhury, K., Stoykova, A., Aparicio, S., Brenner, S., and Gruss, P. 1999. Distinct cis-essential modules direct the time-space pattern of the Pax6 gene activity. Dev. Biol. 205: 79-97.

Koshiba-Takeuchi, K., Takeuchi, J.K., Matsumoto, K., Momose, T., Uno, K., Hoepker, V., Ogura, K., Takahashi, N., Nakamura, H., Yasuda, K., et al. 2000. Tbx5 and the retinotectum projection. Science 287: 134-137.

Leconte, L., Lecoin, L., Martin, P., and Saule, S. 2004. Pax6 interacts with cVax and Tbx 5 to establish the dorsoventral boundary of the developing eye. J. Biol. Chem. 279: 4727247277.

Livesey, F.J. and Cepko, C.L. 2001. Vertebrate neural cell-fate determination: Lessons from the retina. Trends Neurosci. 2: $109-118$.

Macdonald, R., Barth, K.A., Xu, Q., Holder, N., Mikkola, I., and Wilson, S.W. 1995. Midline signalling is required for Pax gene regulation and patterning of the eyes. Development 121: 3267-3278.

Marquardt, T., Ashery-Padan, R., Andrejewski, N., Scardigli, R., Guillemot, F., and Gruss, P. 2001. Pax6 is required for the multipotent state of retinal progenitor cells. Cell 105: 43-55.

Marti, E. and Bovolenta, P. 2002. Sonic hedgehog in CNS development: One signal, multiple outputs. Trends Neurosci. 25: 89-96.

Mi, H. and Barres, B.A. 1999. Purification and characterization of astrocyte precursor cells in the developing rat optic nerve. J. Neurosci. 19: 1049-1061.

Mui, S.H., Hindges, R., O'Leary, D.D.M., Lemke, G., and Bertuzzi, S. 2002. The homeodomain protein Vax2 patterns the dorsoventral and nasotemporal axes of the eye. Development 129: 797-804.

Nakayama, A., Nguyen, M., Chen, C., Opdecamp, K., Hodgkinson, C., and Arnheiter, H. 1998. Mutations in microphtalmia, the mouse homolog of the human deafness gene MITF, affect neuroepithelial and neural crest-derived melanocytes differently. Mech. Dev. 70: 155-166.

Nguyen, M.-T.T. and Arnheiter, H. 2000. Signaling and transcriptional regulation in early mammalian eye development: A link between FGF and MITF. Development 127: 35813591.

Ohkubo, Y., Chiang, C., and Rubenstein, J.L. 2002. Coordinate regulation and synergistic actions of BMP4, SHH and FGF8 in the rostral prosencephalon regulate morphogenesis of the telencephalic and optic vesicles. Neuroscience 111: 1-17.

Ohsaki, K., Morimitsu, T., Ishida, Y., Kominami, R., and Takahashi, N. 1999. Expression of the Vax family homeobox genes suggests multiple roles in eye development. Genes to Cells 4: 267-276.

Perron, M., Odecamp, K., Butler, K., Harris, W., and Bellefroid, E. 1999. X-ngnr-1 and Xath3 promote ectopic expression of sensory neuron markers in the nerula ectoderm and have distinct inducing properties in the retina. Proc. Natl. Acad. Sci. 96: 14996-15001.

Plaza, S., Dozier, C., Langlois, M.C., and Saule, S. 1995. Identification and characterization of a neuroretina-specific enhancer element in the quail Pax-6 (Pax-QNR) gene. Mol. Cell. Biol. 15: 892-903. 
Quiring, R., Walldorf, U., Kloter, U., and Gehring, W.J. 1994. Homology of the eyeless gene of Drosophila to the Small eye gene in mice and Aniridia in humans. Science 265: 785-789.

Reh, T. and Levine, E. 1998. Multipotential stem cells and progenitors in the vertebrate retina. J. Neurobiol. 36: 206-220.

Schulte, D., Furukawa, T., Peters, M.A., Kozak, C.A., and Cepko, C.L. 1999. Misexpression of the Emx-related homeobox genes cVax and $\operatorname{mVax} 2$ ventralizes the retina and perturbs the retinotectal map. Neuron 24: 541-553.

Schwartz, M., Cecconi, F., Bernier, G., Andrejewski, N., Kammandel, B., Wagner, M., and Gruss, P. 2000. Spatial specification of mammalian eye territories by reciprocal transcriptional repression of Pax2 and Pax6. Development 127: 43254334.

Take-uchi, M., Clarke, J.D., and Wilson, S.W. 2003. Hedgehog signalling maintains the optic stalk-retinal interface through the regulation of Vax gene activity. Development 130: $955-968$.

Wang, S.W., Kim, B.S., Ding, K., Wang, H., Sun, D., Johnson, R.L., Klein, W.H., and Gan, L. 2001. Requirement for math5 in the development of retinal ganglion cells. Genes \& Dev. 15: 24-29.

Weinmann, A.S., Bartley, S.M., Zhang, T., Zhang, M.Q., and Farnham, P.J. 2001. Use of chromatin immunoprecipitation to clone novel E2F target promoters. Mol. Cell. Biol. 21: 6820-6832. 


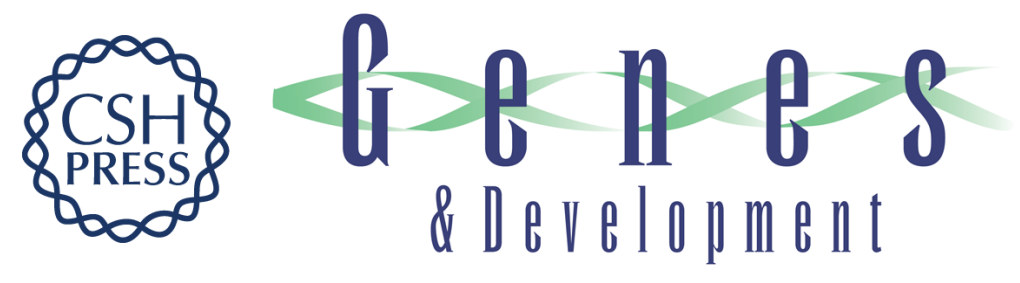

\section{Vax genes ventralize the embryonic eye}

Stina H. Mui, Jin Woo Kim, Greg Lemke, et al.

Genes Dev. 2005, 19:

Access the most recent version at doi:10.1101/gad.1276605

References This article cites 38 articles, 20 of which can be accessed free at: http://genesdev.cshlp.org/content/19/10/1249.full.html\#ref-list-1

License

Email Alerting Receive free email alerts when new articles cite this article - sign up in the box at the top Service right corner of the article or click here.

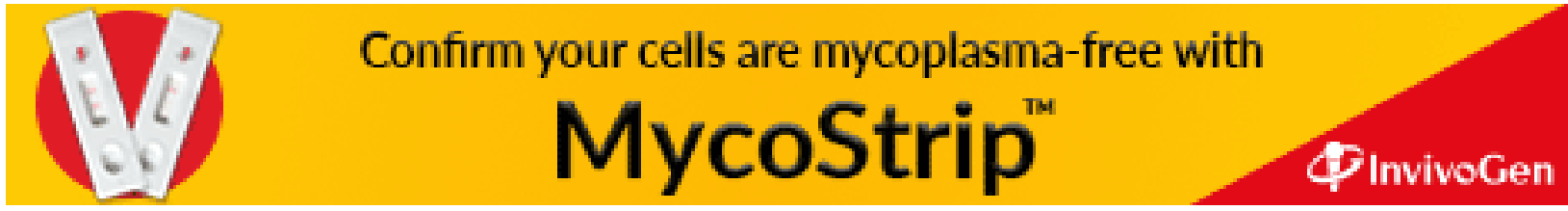

